\title{
Prevalence of antibodies against leptospires in small mammals in relation to age, sex and season
}

\author{
František Treml ${ }^{1}$, Jiří Nepeřený ${ }^{2}$, Eva Janová ${ }^{1}$, Hana Band'ouchová ${ }^{\text {, Jiří Pikula }}{ }^{3}$ \\ ${ }^{1}$ Department of Infectious Diseases and Microbiology, Faculty of Veterinary Medicine, University of Veterinary \\ and Pharmaceutical Sciences Brno, Czech Republic \\ ${ }^{2}$ Bioveta Ivanovice na Hané, Czech Republic \\ ${ }^{3}$ Department of Veterinary Ecology and Environmental Protection, Faculty of Veterinary Hygiene and Ecology, \\ University of Veterinary and Pharmaceutical Sciences Brno, Czech Republic
}

\author{
Received November 24, 2011 \\ Accepted April 11, 2012
}

\begin{abstract}
A total of 2,195 small mammals belonging to 8 species were captured in different districts of South Moravia, Czech Republic, and examined for antibodies against leptospires in the period from 2004 to 2008. Positive specimens amounting to $173(9 \%)$ were found annually in five species of rodents such as Apodemus sp., Clethrionomys glareolus, Microtus arvalis, Mus musculus and Rattus norvegicus. The recognised leptospiral serotypes included L. grippotyphosa, L. bulgarica, L. sejroe and L. icterohaemorrhagiae/copenhageni. The highest prevalence of antibodies was against the L. grippotyphosa serotype $(92.8 \%)$. Reactions with other serotypes of leptospires were exceptional. Reactions with $L$. bulgarica antigen were only due to coagglutination with $L$. grippotyphosa leptospires. The titres ranged from 100 to 12,800 . However, lower values up to the titre of 800 predominated in 151 cases $(83.4 \%)$. There were non-significant sex differences in seroprevalence with $8.1 \%$ and $7.6 \%$ prevalence in males and females, respectively. Marked differences were, however, found in seroprevalence of juveniles and adults with $3.3 \%$ and $10.2 \%$, respectively. Adult males and females were seropositive in $10.9 \%$ and $9.5 \%$, respectively; juveniles were seropositive only in $3.0 \%$ and $3.7 \%$. The highest percentage of specimens $(43.6 \%)$ was examined during July and August. The summer seroprevalence of $10.9 \%$ was higher than in spring and autumn. Our results revealed the persistence of both natural and synanthropic nidi of leptospirosis in the region under study and demonstrated epidemiological implications regarding health protection of animals and humans.
\end{abstract}

Wild rodents, insectivores, leptospiroses, L. grippotyphosa, serology, antibodies

Leptospiroses belong to serious bacterial infectious diseases of animals and humans receiving a great deal of attention as important zoonoses (Teichman et al. 2001; Bharti et al. 2003; Treml et al. 2007). Extensive epidemics and epizootics were particularly reported from tropical and subtropical regions (Vijayachari et al. 2008). The disease, however, is not restricted to the tropics and can occur in whichever country around the world (Teichman et al. 2001; Vijayachari et al. 2008).

The morbidity in the human population, however, is relatively low compared to other infectious diseases (Teichman et al. 2001). There are approximately 0.3 to 0.9 cases per 100,000 inhabitants in the Czech Republic. The actual incidence of the disease is probably higher because some cases are misdiagnosed (Zitek and Benes 2005). The abovementioned facts also concern veterinary medicine (Stanko et al. 1997; Treml et al. 2002; Cvetnic et al. 2003).

Leptospirosis, a disease of seasonal occurrence, is reported mainly in summer and autumn months when humans as well as animals get frequently into contact with reservoir animals and contaminated environments (Anjanin 1971; Colavita and Paoletti 2007). Leptospires as causative agents are typical parasites of animals, rodents and insectivores, in particular, because life at the expense of the host is their species specific characteristic. Each serotype of leptospires has its own predilection host considered as the main reservoir

Address for correspondence:

Prof. MVDr. František Treml, CSc.

Department of Infectious Diseases and Microbiology

Faculty of Veterinary Medicine

University of Veterinary and Pharmaceutical Sciences Brno

Palackého tř. 1-3, 61242 Brno, Czech Republic

Phone: +420 541562379

E-mail: tremlf@vfu.cz

http://actavet.vfu.cz/ 
animal (Anjanin 1971; Sebek and Rosicky 1974; Bharti et al. 2003). These reservoir animals are then responsible for the origin and persistence of endemic nidi of leptospiroses. Primary infections of reservoir animals are frequently accompanied by the shedding of bacteria into the external environment essential for their circulation under natural conditions where leptospires survive mainly in aquatic habitats (Colavita and Paoletti 2007).

However, under favourable conditions other small and larger mammalian species or even humans may become infected. The most reliable and precise information on the occurrence and serotypic aetiology of natural and synanthropic nidi of leptospiroses are obtained through research aimed at studies of natural reservoirs. Great attention was paid to the geographic distribution of natural nidi of leptospiroses, and their biotic and spatial structures in the Czech Republic (Sebek and Rosicky 1974).

The aim of the present study is long-term monitoring of the occurrence of antibodies against different serotypes of leptospires within a previously recognized endemic region. Our aim was also to examine temporal aspects of natural nidi of leptospiroses under natural and synanthropic conditions and the prevalence of antibodies against leptospires in small mammals in relation to age, sex and season.

\section{Materials and Methods}

Small mammalian species were captured in different districts of South Moravia, Czech Republic, using commercially available snap traps for five years from 2004 to 2008. Traps were placed in lines, left for three days and regularly checked in natural habitats as well as around farming buildings during spring (April, May), summer (July, August) and autumn (October, November) months.

A total of 2,195 small mammals belonging to 8 species were captured and examined (i.e., field mice Apodemus sp., pygmy field mouse Apodemus microps, bank vole Clethrionomys glareolus, lesser white-toothed shrew Crocidura suaveolens, common vole Microtus arvalis, house mouse Mus musculus, brown rat Rattus norvegicus, common shrew Sorex araneus).

On autopsy and the abdominal cavity examination, they were classified into age and sex groups using the classification by Pelikan (1970). Heart eluates or blood filtration paper imprints were used for the serological examination. Serological examination was based on the reaction of agglutination lysis using standard methods (Sebek 1979). The following 10 serotypes and strains of leptospires were used for the testing: L. grippotyphosaP 125, L. icterohaemorrhagiae - Fryšava, L. sejroe - M 84, L. canicola - C 7, L. pomona -- Simon, L. bratislava - Jež Bratislava, L. arboreae - M 7, L. sorex jalna - Sorex Jalná, L. bulgarica - Nikolaevo, L. pyrogenes Salinem. Sera reacting in the standard dilution of 1:100 were examined with the respective serotype up to the titre. Differences in the prevalence of seropositive cases between males and females, juvenile and adult animals were evaluated using $t$-test for comparison of paired relative values.

\section{Results}

As shown in Table 1, species such as Apodemus sp. $(\mathrm{n}=981)$, Microtus arvalis $(\mathrm{n}=578)$ and Clethrionomys glareolus $(\mathrm{n}=570)$ were the most frequent in the collection of small mammals; others were captured less often. Positive specimens amounting to $173(7.9 \%)$, were found in five species of rodents such as Apodemus sp., Clethrionomys glareolus, Microtus arvalis, Mus musculus and Rattus norvegicus.

A total of 165 small mammals $(7.5 \%)$ were positive with only one leptospiral antigen (L. grippotyphosa, L. sejroe, L. icterohaemorrhagiae resp. copenhageni) and there were 8 cases $(0.4 \%)$ positive against two antigens (both L. grippotyphosa and L. bulgarica).

As follows from Table 2, the L. grippotyphosa serotype prevailed in the positive cases and amounted to 168 specimens ( $92.8 \%$ of all positive). Reactions with other serotypes of leptospires were only exceptional. There were 3 cases of $L$. sejroe $(1.6 \%)$ and 2 cases of L. icterohaemorrhagiae/copenhageni (1.1\%). Reactions with L. bulgarica antigen were only due to coagglutination with L. grippotyphosa leptospires.

Table 2 demonstrates that the highest percentage of titres ranging from 100 to 800 was found in 151 cases $(83.4 \%)$. Higher titres ranging from 1600 to 12,800 were found rather exceptionally in 30 specimens $(16.6 \%)$ of positive reactions against L. grippotyphosa, L. sejroe, and L. icterohaemorrhagiae/copenhageni serotypes. 
Table 1. Numbers of examined and positive small mammalian species for leptospiral serotypes in years 2004-2008.

\begin{tabular}{|c|c|c|c|}
\hline Species & Total & Positive (\%) & Serotypes of Leptospira \\
\hline Field mouse & 981 & $74(7.5)$ & $69 \times$ L. grippotyphosa \\
\hline Apodemus sp. & & & $5 \times L$ grippotyphosa $\times$ L. bulgarica \\
\hline Pygmy field mouse & 23 & 0 & \\
\hline \multicolumn{4}{|l|}{ Apodemus microps } \\
\hline Bank vole & 570 & $11(1.9)$ & $11 \times$ L. grippotyphosa \\
\hline \multicolumn{4}{|l|}{ Clethrionomys glareolus } \\
\hline Lesser white-toothed shrew & 4 & 0 & \\
\hline \multicolumn{4}{|l|}{ Crocidura suavaeolens } \\
\hline Common vole & 578 & $83(14.4)$ & $80 \times$ L. grippotyphosa \\
\hline Microtus arvalis & & & $3 \times$ L. grippotyphosa $\times$ L. bulgarica \\
\hline House mouse & 32 & $3(9.4)$ & $3 \times$ L. sejroe \\
\hline \multicolumn{4}{|l|}{ Mus musculus } \\
\hline Brown rat & 3 & $2(66.6)$ & $2 \times$ L. icterohaemorrhagiae \\
\hline \multicolumn{4}{|l|}{ Rattus norvegicus } \\
\hline Common shrew & 4 & 0 & \\
\hline \multicolumn{4}{|l|}{ Sorex araneus } \\
\hline Total & 2195 & $173(7.9)$ & $\begin{aligned} 160 & \times \text { L. grippotyphosa } \\
8 & \times \text { L. grippotyphosa } \times \text { L. bulgarica } \\
2 & \times \text { L. icterohaemorrhagiae } \\
3 & \times \text { L. sejroe }\end{aligned}$ \\
\hline
\end{tabular}

Table 2. Leptospiral serotypes and titres found in the examined small mammalian species.

\begin{tabular}{|c|c|c|c|c|c|c|c|c|c|}
\hline \multirow{2}{*}{$\begin{array}{l}\text { Serotypes } \\
\text { of Leptospira }\end{array}$} & \multirow{2}{*}{$\begin{array}{c}\text { Positive } \\
(\%)\end{array}$} & \multicolumn{8}{|c|}{ Titres } \\
\hline & & 100 & 200 & 400 & 800 & 1600 & 3200 & 6400 & 12800 \\
\hline L. grippotyphosa & $168(92.8)$ & 47 & 21 & 51 & 23 & 14 & 5 & 2 & 5 \\
\hline L. icterohaemorrhagiae & $2(1.1)$ & 0 & 0 & 0 & 0 & 1 & 0 & 1 & 0 \\
\hline L. sejroe & $3(1.6)$ & 0 & 0 & 1 & 0 & 1 & 0 & 1 & 0 \\
\hline L. canicola & 0 & 0 & 0 & 0 & 0 & 0 & 0 & 0 & 0 \\
\hline L. Jež Bratislava & 0 & 0 & 0 & 0 & 0 & 0 & 0 & 0 & 0 \\
\hline L. pomona & 0 & 0 & 0 & 0 & 0 & 0 & 0 & 0 & 0 \\
\hline L. sorex jalna & 0 & 0 & 0 & 0 & 0 & 0 & 0 & 0 & 0 \\
\hline L. bulgarica & $8(4.4)$ & 4 & 2 & 1 & 1 & 0 & 0 & 0 & 0 \\
\hline Total & $\begin{array}{c}181 \\
(100)\end{array}$ & $\begin{array}{c}51 \\
(28.2)\end{array}$ & $\begin{array}{c}23 \\
(12.7)\end{array}$ & $\begin{array}{c}53 \\
(29.3)\end{array}$ & $\begin{array}{c}24 \\
(13.2)\end{array}$ & $\begin{array}{l}16 \\
(8.8)\end{array}$ & $\begin{array}{c}5 \\
(2.8)\end{array}$ & $\begin{array}{c}4 \\
(2.2)\end{array}$ & $\begin{array}{c}5 \\
(2.8)\end{array}$ \\
\hline
\end{tabular}

As shown in Fig. 1 there were non-significant differences in seroprevalence of positive males and females that amounted to $8.1 \%$ and $7.6 \%$, respectively. On the other hand, marked differences were found in seroprevalence of juveniles and adults, i.e. $3.3 \%$ and $10.2 \%$, respectively. Adult males and females were seropositive in $10.9 \%$ and $9.5 \%$, respectively; juveniles only in $3.0 \%$ and $3.7 \%$.

Considering seasonal differences, the highest numbers of small mammals were captured in the summer $(\mathrm{n}=948$ specimens, $43.2 \%)$; autumn and spring numbers amounted to 808 $(36.8 \%)$ and $439(20.0 \%)$ small mammals, respectively. Antibodies-against-leptospires positive specimens were found in all seasons of the study and amounted to $4.8 \%, 10.8 \%$ and $6.1 \%$ in spring, summer and autumn, respectively. The highest prevalence of positive specimens was found in the summer. 


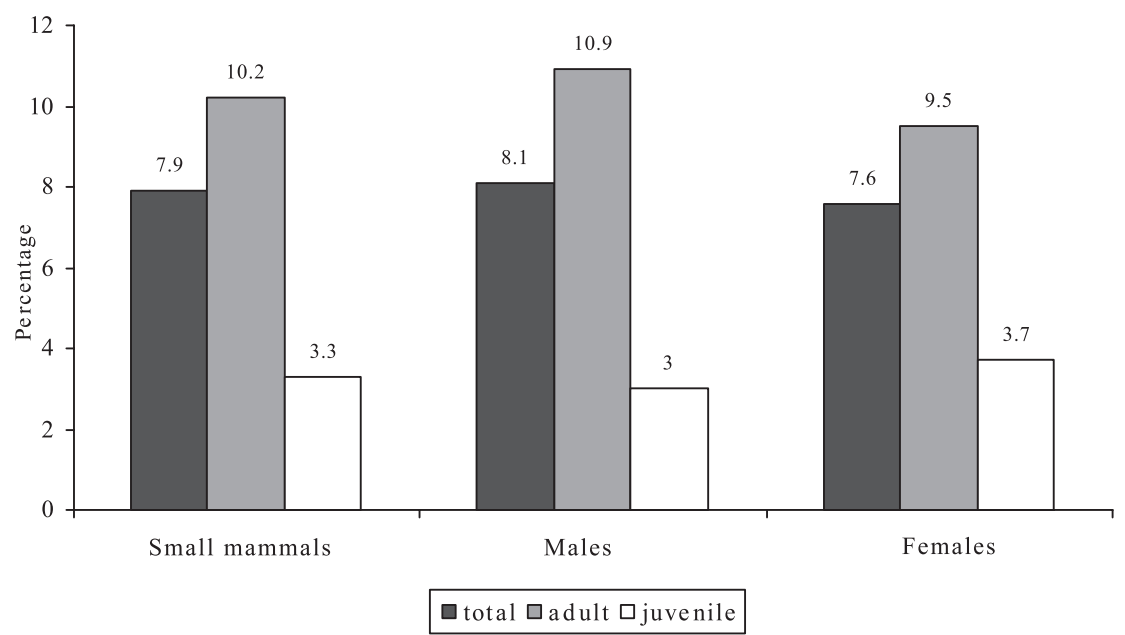

Fig. 1. Prevalence of antibodies against leptospires in relation to sex and age

\section{Discussion}

Leptospirosis is a typical infectious disease of natural nidality persisting for long periods in areas of favourable conditions. The whole of South Moravia with its agricultural components can be considered such an area providing favourable conditions for the occurrence and survival of wild as well as synanthropic small mammals that can be reservoirs of various serotypes of leptospires (Anjanin 1971).

The collected 2,195 specimens used in our study belonged to 8 species of exoanthropic and synanthropic mammalian species. Structure of the small mammalian community in the territory under study was similar to the previously described condition (Treml et al. 2002). Specimens of the common vole (Microtus arvalis) and the fieldmouse group (Apodemus $s p$.) prevailed both in our previous and present studies. The occurrence of the common vole, in particular, is very important. In some authors' opinion common voles are the main reservoir of the L. grippotyphosa serotype and outbreaks of the disease are associated with its overcrowding events (Sebek and Rosicky 1974).

Antibodies against the above-mentioned serotype of leptospires prevailed also in our study and amounted to $92.8 \%$ of positive reactions. This result documents the ongoing persistence of this type of natural nidi of leptospires bound to the population of the common vole (Sebek and Rosicky 1974). Other species of exoanthropic mammals played rather the role of potential hosts and as our results show, the prevalence of antibodies against leptospires was always lower than in the common vole both in our present and previous studies (Treml et al. 2002).

According to Sebek and Rosicky (1974) these potential hosts play a more important role during periods of low population numbers of the main reservoir host, i.e. the common vole. Transmission of the infection within and among species occurs via direct contacts or indirectly through contaminated water. Except for the grippotyphosa-type, no other nidi of leptospirosis were found in the open country. This is also in agreement with previous reports from other regions of the Czech Republic (Sebek and Rosicky 1974; Vosta et al. 1977).

Two species of synanthropic mammals, i.e., the house mouse (Mus musculus) and the Norwegian rat (Rattus norvegicus), were found positive, though on a sporadic basis, for 
L. sejroe and L. icterohaemorrhagiae/copenhageni serotypes of leptospires. Both these species are considered the main reservoirs of the above-mentioned serotypes (Anjanin 1971). As follows from a study by Zitek and Benes (2005) and reports of the Czech National Institute of Public Health these serotypes of leptospires are most commonly encountered in human infections. Infections with the L. grippotyphosa serotype prevail in human population as well as in animals (Zitek and Benes 2005). Positive findings of the L. bulgarica serotype in five specimens of field mice (Apodemus sp.) and three specimens of common voles (Microtus arvalis) were probably the result of the so-called coagglutination due to the presence of antibodies against the L. grippotyphosa serotype amounting to higher titres in these animals. It is also necessary to consider the possibility of coagglutination with other leptospiral serotypes as part of diagnostic evaluation (Sebek 1979).

Seroprevalence for leptospirosis in males nearly equalled to that in females (8.1 and $7.6 \%$, respectively). In contrast to this, Karaseva et al. (1973) found higher percentage of infected males and thought it to be associated with more frequent skin injuries.

Interestingly, marked differences were found when evaluating seroprevalence in relation to age of small mammals. Juveniles and adults were positive in $3.3 \%$ and $10.2 \%$, respectively. Adult males and females were seropositive in $10.9 \%$ and $9.5 \%$, respectively, whereas juveniles only in 3.0\% and 3.6\%. Similar findings were reported by Stanko et al. (1997) from Slovakia.

The population numbers of rodents, potential reservoirs of leptospiral serotypes, are known to fluctuate seasonally. The most important population trends are associated with increased sexual activities in spring and higher population densities in summer and autumn (Pelikan 1970). Analysis of numbers of small mammals captured in different seasons revealed the highest percentage of $43.2 \%$ in summer months (July and August). Similarly, the prevalence of antibodies was the highest in summer $(10.8 \%)$, decreased in autumn $(6.1 \%)$ and the lowest in spring $(4.8 \%)$.

Our results demonstrate that summer and autumn months posed a greater threat of leptospirosis in humans and animals due to direct contacts with reservoir hosts showing higher seroprevalence or contaminated environmental components in natural nidi.

\section{Acknowledgements}

The Ministry of Education, Youth and Sports is gratefully acknowledged for project No. MSM 6215712402.

\section{References}

Anjanin VV 1971: Leptospiroses in humans and animals (In Russian). Medicina, Moskva, 351 p.

Bharti AR, Nally JE, Ricaldi JN, Matthias MA, Diaz MM, Lovett MA, Levett PN, Gilman RH, Willig MR, Gotuzzo E, Vinetz JM 2003: Leptospirosis: a zoonotic disease of global importance. Lancet Infect Dis 3: 757-771

Cvetnic Z, Margaletic J, Toncic J, Turk N, Milas Z, Spicic S, Lojkic M, Terzic S, Jemersic L, Humski A, Mitak M, Habrun B, Krt B 2003: A serological survey and isolation of leptospires from small rodents and wild boars in the Republic of Croatia. Vet Med - Czech 48: 321-329

Colavita G, Paoletti M 2007: Leptospirosis: occupational risk in the chain of food of animal origin. G Ital Med Lav Ergon 29: 21-24

Karaseva EV, Chernukha YG, Piskunova LA 1973: Results of studying the time of survival of pathogenic leptospira under natural conditions. J Hyg Epidemiol Microbiol Immunol 17: 339-345

Pelikan J 1970: Sex ratio in three Apodemus species (In Czech). Zool Listy 19: 23-34

Stanko M, Prokopcakova H, Peterkova J, Cislakova L 1997: Relation between characteristics of the small mammal population and occurrence of Leptospira antibodies (In Slovak). Vet Med - Czech 42: 355-360

Sebek Z 1979: Standard methods of laboratory diagnostics of leptospiroses (In Czech). Acta Hyg Epidemiol Microbiol, Suppl 2, 18 p.

Sebek Z, Rosicky B 1974: On the occurrence, characteristics and structure of the foci of leptospirosis in Czechoslovakia (In Czech). Čs. Epidemiol Mikrobiol Imunol 23: 10-21 
Teichmann D, Göbels K, Simon J, Grobusch MP, Suttorp N 2001: A severe case of leptospirosis acquired during an iron man contest. Eur J Clin Microbiol Infect Dis 20: 137-138

Treml F, Pejcoch M, Holesovska Z 2002: Small mammals - natural reservoir of pathogenic leptospires. Vet Med - Czech 47: 309-314

Treml F, Pikula J, Bandouchova H, Horakova J 2007: European brown hare as a potential source of zoonotic agents. Vet Med - Czech 52: 451-456

Vijayachari P, Sugunan AP, Shriram AN 2008: Leptospirosis: an emerging global public health problem. J Biosci 33: $557-569$

Vosta J, Hanak P, Vychodil J 1977: Effect of population dynamics of small mammals on spread and survival of Leptospira grippotyphosa in foci (In Czech). Bratisl Lek Listy 68: 50-56

Zitek K, Benes C 2005: Longitudinal epidemiology of leptospirosis in the Czech Republic (1963-2003). Epidemiol Mikrobiol Imunol 54: 21-26 